\title{
Implementasi Program Pos Pembinaan Terpadu Penyakit Tidak Menular di Provinsi Jawa Barat Tahun 2015
}

\author{
Implementation of Posbindu Program For Noncommunicable Diseases In \\ Jawa Barat Province
}

\author{
Lelly Andayasari ${ }^{1}$, Cicih Opitasari ${ }^{1}$ \\ 1) Pusat Penelitian dan Pengembangan Sumber Daya dan Pelayanan Kesehatan, Jalan Percetakan Negara No. 29 Jakarta \\ 10560, Indonesia \\ Korespondensi: andayasari@gmail.com
}

Submitted: 3 September 2019, Revised: 2 Desember 2019, Accepted: 13 Desember 2019

https://doi.org/10.22435/jpppk.v3i3.2713

\begin{abstract}
Abstrak
Pos Pembinaan Terpadu Penyakit Tidak Menular (Posbindu PTM) merupakan salah satu bentuk pemberdayaan peran serta masyarakat untuk pengendalian penyakit tidak menular. Saat ini terjadi peningkatan prevalensi penyakit tidak menular di Indonesia. Tujuan penelitian adalah untuk mengidentifikasi implementasi program Posbindu PTM di Provinsi Jawa Barat. Desain penelitian ini adalah potong lintang. Data yang dikumpulkan adalah data kuantitatif dan kualitatif. Data kualitatif diperoleh melalui wawancara mendalam dan focus group discussion. Informan utama berasal dari Dinas Kesehatan, Puskesmas, kader, dan masyarakat. Data kuantitatif didapatkan dari 187 responden yang berkunjung ke Posbindu PTM. Sebagian besar adalah perempuan dan berumur 45 tahun ke atas. Faktor pendukung pelaksanaan program Posbindu PTM adalah adanya pedoman Posbindu PTM, Posbindu kit, kader yang mampu mengidentifikasi faktor risiko PTM, kesiapan tenaga medis dan paramedik dalam penanganan PTM, serta adanya dukungan dari kepala Dinas kesehatan dalam menangani PTM. Sedangkan faktor penghambatnya adalah dana yang terbatas, kurang lengkapnya penyuluhan yang diberikan kader, kurangnya dukungan dari perangkat desa, dan tidak adanya tenaga medis/paramedik. Perlu peningkatan sosialisasi program Posbindu PTM dalam meningkatkan kesadaran terhadap kesehatan, serta dilengkapinya Buku Pedoman Posbindu PTM dan Posbindu kit untuk masing-masing Posbindu PTM.
\end{abstract}

Kata kunci: Posbindu PTM, kader, dana, PTM

\section{Abstract}

Integrated coaching post for non-communicable diseases (Posbindu PTM) is a form of empowering community participation to control non-communicable diseases (NCDs). Currently, there is an increase in the prevalence of NCDs in Indonesia. The aim of this study was to identify the implementation of the Posbindu PTM program in West Java Province. This was a cross sectional study. The data collected was quantitative and qualitative data. Qualitative data were obtained through in-depth interviews and focus group discussions. The informants of the study came from the district health agency, public health centers, cadres and the community. A total of 187 participants visiting Posbindu PTM were interviewed, mostly were women and aged $\geq 45$ years. Supporting factors for the implementation of the Posbindu PTM program are the availability of guidelines and Posbindu kit, capability of cadres to identify the risk factors of NCDs, readiness of medical and paramedical personnel in non communicable management and the support from the head of the health department in non communicable management. The inhibiting factors are limited budget, lack of counseling by cadres, lack of support from village officials, and lack of medical/ paramedical personnel. It is necessary to increase the socialization of the Posbindu PTM program in increasing awareness of their health and to complete the guidelines and kits for each Posbindu PTM.

Keywords: Posbindu PTM, cadres, funding, PTM 


\section{Pendahuluan}

Indonesiamenghadapi transisi epidemiologi, yaitu prevalensi penyakit tidak menular (PTM) meningkat, sementara penyakit menular masih menjadi masalah pada daerah tertentu. Peningkatan prevalensi PTM terutama hipertensi terjadi akibat gaya hidup tidak sehat yang dipacu oleh urbanisasi, modernisasi dan globalisasi. ${ }^{1}$ Hal tersebut menjadi ancaman yang serius dalam pembangunan, karena mengancam pertumbuhan ekonomi nasional. Untuk itu dikembangkan model pengendalian PTM melalui Posbindu PTM. ${ }^{2}$

Sejak tahun 2001 Pemerintah membentuk Pos pembinaan terpadu (Posbindu) PTM. Posbindu merupakan salah satu bentuk pemberdayaan dan peningkatan peran serta masyarakat, dari masyarakat, oleh masyarakat dan untuk masyarakat. Posbindu terdiri dari dua yaitu Posbindu penyakit tidak menular (PTM) dan Posbindu lansia. Posbindu PTM diperuntukkan bagi masyarakat usia di atas 15 tahun, sedangkan Posbindu lansia diperuntukkan bagi lansia usia $\geq 60$ tahun.

Posbindu PTM adalah suatu bentuk pelayanan yang melibatkan peran serta masyarakat melalui upaya promotif dan preventif untuk mendeteksi dan mengendalikan secara dini keberadaan faktor risiko penyakit tidak menular (PTM). ${ }^{3}$ Peran pemerintah memberikan fasilitas dan bimbingan untuk pengendalian faktor risiko PTM dengan dibekali pengetahuan dan keterampilan untuk melakukan deteksi dini, pemantauan faktor risiko serta tindak lanjutnya. Penyakit tidak menular terdiri dari penyakit kardiovaskuler, diabetes mellitus (DM), Kanker dan Penyakit Paru Obstruktif Kronis (PPOK).

Penyakit tidak menular diantaranya hipertensi dan diabetes mellitus. Menurut WHO tahun 2011, satu miliar orang di dunia menderita hipertensi, dua pertiga diantaranya berada di negara berkembang yang berpenghasilan rendah-sedang. Prevalensi penyakit hipertensi akan terus meningkat, diprediksikan pada tahun 2025 sekitar 29\% orang dewasa di seluruh dunia menderita hipertensi. Hipertensi telah mengakibatkan kematian sekitar 8 juta orang setiap tahun, 1,5 juta kematian terjadi di Asia Tenggara yang sepertiga populasinya menderita hipertensi. ${ }^{4,5}$ Berdasarkan hasil Riskesdas 2013 prevalensi hipertensi pada penduduk umur 18 tahun keatas di Indonesia adalah sebesar 25,8\%, lima provinsi prevalensi tertinggi yaitu provinsi Bangka Belitung 30,9\%, Kalimantan Selatan 30,8\%, Kalimantan Timur 29,6\%, Jawa Barat 29,4\% dan Gorontalo 29,0\%.

Berdasarkan latar belakang tersebut di atas, maka timbul pertanyaan mengapa prevalensi PTM di Indonesia masih tinggi dan apakah Posbindu PTM yang sudah terbentuk tidak dapat beroperasi secara optimal serta bagaimana strategi agar masyarakat memanfaatkan Posbindu PTM.

Tujuan penelitian ini adalah untuk mengidentifikasi implementasi penerapan Permenkes Nomor 65 Tahun 2013 tentang Program Posbindu Penyakit Tidak Menular di Provinsi Jawa Barat.

\section{Metode}

Penelitian ini adalah riset operasional dengan disain potong lintang, menggunakan pendekatan kualitatif dan kuantitatif. Penelitian dilakukan di Provinsi Jawa Barat (Kota Cimahi dan Kab. Cirebon) pada tahun 2015. Alasan pemilihan Provinsi Jawa Barat karena provinsi ini termasuk dalam lima provinsi dengan angka prevalensi hipertensi dan DM tertinggi di Indonesia. ${ }^{6}$ Pemilihan Kota Cimahi dan Kabupaten Cirebon dilakukan secara acak sederhana. Posbindu PTM dipilih secara purposive berdasarkan kriteria beroperasi rutin di tahun 2015 dan minimal memiliki satu orang kader terlatih. Jumlah Posbindu PTM yang memenuhi kriteria sebanyak 10 Posbindu, masing-masing 5 Posbindu PTM di Kota Cimahi dan 5 Posbindu PTM di Kabupaten Cirebon.

Populasi adalah penduduk berusia 15 tahun keatas di Provinsi Jawa Barat. Populasi terjangkau adalah penduduk berusia 15 tahun keatas yang memanfaatkan Posbindu PTM. Sampel untuk studi kuantitatif adalah penduduk berusia 15 tahun keatas yang memanfaatkan Posbindu PTM di lokasi penelitian. Pemilihan sampel dilakukan secara purposive yang memenuhi kriteria inklusi yaitu penduduk yang berusia 15 tahun keatas yang memanfaatkan pelayanan Posbindu PTM di daerah penelitian. Total sampel yang memenuhi kriteria inklusi di 10 Posbindu PTM sebanyak 187 responden.

Informan untuk studi kualitatif sebanyak 15 
informan yang terdiri dari Kepala Bidang Program PTM Dinkes Provinsi dan atau Penanggungjawab Program Posbindu PTM Dinkes Provinsi (1 orang); Kepala Dinkes kab/kota dan atau Penanggungjawab Program Posbindu PTM Dinkes kab/kota (4 orang); dan 10 tokoh masyarakat dari masing-masing Posbindu PTM. Untuk mendapatkan gambaran pelaksanaan Posbindu PTM yang dilakukan oleh kader Posbindu PTM dan Penanggungjawab Posbindu PTM dilakukan Focus Group Discussion (FGD). Jumlah FGD kader adalah 2 FGD masingmasing 1 FGD kader untuk tiap kabupaten/ kota, demikian juga FGD Penanggungjawab Posbindu PTM masing-masing 1 FGD PJ Posbindu PTM untuk tiap kabupaten/ kota. Sehingga jumlah FGD adalah 4. Informan yang dipilih untuk wawancara ditetapkan secara langsung menggunakan prinsip kesesuaian dan kecukupan.

Instrumen yang digunakan adalah panduan wawancara mendalam, panduan focus group discussion (FGD) dan kuesioner terstruktur. Teknik yang digunakan dalam penelitian yaitu wawancara mendalam, FGD dan observasi. Pengumpulan data dilaksanakan pada Bulan Juni sampai dengan Agustus 2015.

Data kuantitatif dianalisis secara deskriptif. Umur dikelompokkan menjadi dua yaitu 15-44 tahun dan $\geq 45$ tahun. Tingkat pendidikan dikelompokkan menjadi tiga, yaitu pendidikan rendah (tidak sekolah, tidak tamat SD, tamat SD), pendidikan sedang (tamat SLTP, tamat SLTA) dan pendidikan tinggi (tamat diploma/PT dan Pasca Sarjana).

Pengumpulan data kualitatif menggunakan wawancara mendalam, FGD dan observasi. Wawancara mendalam dilakukan oleh tim peneliti untuk memperoleh data gambaran pelaksanaan Posbindu PTM dengan menggunakan pedoman wawancara mendalam yang telah diujicobakan sebelumnya. Untuk menunjang pelaksanaan pengumpulan data maka peneliti melakukan wawancara mendalam kepada informan. Informan terdiri dari Kepala Dinas Kesehatan Kabupaten/ Kota, Penanggungjawab Program Posbindu PTM dan tokoh masyarakat. Focus group discussion dipandu oleh tim peneliti untuk memperoleh masukan dan informasi maupun permasalahan pelaksanaan Posbindu PTM dengan menggunakan panduan FGD yang sudah diujicobakan. FGD terdiri dari dua kelompok yaitu FGD kader Posbindu PTM dan FGD penanggungjawab Posbindu PTM (Puskesmas). Pengumpulan data juga dilakukan dengan mengamati langsung pelaksanaan Posbindu PTM dengan menggunakan checklist observasi. Observasi dilakukan untuk mendapatkan gambaran pelaksanaan Posbindu PTM, pengamatan terhadap cara pengukuran dan pemeriksaan, Posbindu kit, pedoman Posbindu PTM, dan lain-lain. Pengumpulan data dihentikan apabila peneliti telah mendapatkan data yang sama (data jenuh) pada beberapa informan. Untuk menjamin keabsahan data dalam hal menyangkut data yang valid, reliable dan obyektif, maka peneliti melakukan upaya-upaya seperti diskusi dengan informan atau triangulasi sumber dan memberi check serta dukungan alat bantu untuk mendokumentasikan setiap proses dalam tahap pengumpulan data.

Pengumpulan data kualitatif berlangsung secara interaktif dan terus-menerus sehingga datanya jenuh. Analisis data dilakukan mencakup pembuatan matriks hasil wawancara mendalam dengan informan dan menangkap kutipan yang menguatkan hasil penelitian. Triangulasi yang diterapkan dengan menggunakan triangulasi metode, sumber, dan data. Selain itu, analisis data dilakukan dengan membuat word cloud untuk memetakan pihak-pihak yang cukup penting dalam keberlanjutan program Posbindu PTM.

Analisis data kualitatif dilakukan secara induktif terhadap informasi berupa pendapat dalam bentuk kata-kata, ungkapan atau narasi yang diungkapkan informan penelitian dan data hasil observasi. Analisis data menggunakan model Miles dan Huberman. ${ }^{7}$ Aktivitas dalam analisis data meliputi data reduction, data display dan conclusion drawing/verification. Pada tahap reduksi peneliti merangkum, memilih hal-hal yang pokok, memfokuskan pada hal-hal yang penting dan mencari tema serta polanya. Selanjutnya peneliti melakukan data display. Peneliti dalam melakukan analisis pola dan menentukan data berdasarkan hubungan antar pola. Tahap berikutnya adalah conclusion drawing/ verification. Peneliti memilih hal-hal yang penting untuk membuat kategori dan membuang yang tidak dipakai untuk mengambil kesimpulan. ${ }^{7}$ Persetujuan etik penelitian diperoleh dari Komisi Etik Penelitian Kesehatan, Badan Litbang Kesehatan RI nomor 
LB.02.01/5.2/KE/256/2015 tanggal 4 Mei 2015.

Hasil

Penelitian ini berhasil mengumpulkan data 187 responden di 10 Posbindu PTM di Kota Cimahi dan Kabupaten Cirebon. Hasil Focus Group discussion sebanyak 2 FGD kader dan 2 FGD penanggungjawab Posbindu PTM.

Tabel 1 menunjukkan sebagian besar responden yang berkunjung ke Posbindu PTM adalah perempuan. Hal senada diungkapkan oleh tokoh masyarakat yang mengatakan bahwa...

"Kebanyakan perempuan sedangkan yang laki-laki jarang karena mereka tidak ingin mengontrol badan dan kesehatannya jadi tidak datang. Mungkin karena pekerjaan juga. Tapi ada juga yang tidak kerja tapi tidak datang. Malahan yang kerja tetep datang dan ijin dulu untuk kesini kemudian kembali ke tempat kerja." (Tokoh masyarakat)

Demikian pula yang diungkapkan saat FGD.

"Usia 15 tahun tapi tidak ada usia tersebut yang datang, yang ada usia 20 tahun keatas, laki dan perempuan. Tapi umumnya perempuan". (FGD kader Posbindu)

Sebagian besar responden yang berkunjung ke Posbindu PTM berumur 45 tahun ke atas. Sasaran program Posbindu PTM adalah usia 15 tahun ke atas, hal ini senada dengan yang diungkapkan oleh informan saat FGD...

"Kalau di lapangan sih bu, kalau misalnya itu memang umur 15 sampai 80 lah ya. Tapi kebanyakan yang di lapangan, kebanyakan kadang-kadang ibu-ibu yang sudah 30 keatas, kalau misalnya remaja itu kadang-kadang diceramahin dulu, dikasih pengarahan dulu baru mereka mau ke

Tabel 1. Gambaran Sosiodemografi Responden Posbindu PTM di Provinsi Jawa Barat

\begin{tabular}{|c|c|c|c|c|}
\hline \multirow[t]{2}{*}{ Karakteristik } & \multicolumn{2}{|c|}{ Kota Cimahi } & \multicolumn{2}{|c|}{ Kabupaten Cirebon } \\
\hline & n & $\%$ & $\mathbf{n}$ & $\%$ \\
\hline \multicolumn{5}{|l|}{ Jenis Kelamin } \\
\hline Laki-laki & 20 & 19,8 & 4 & 4,7 \\
\hline Perempuan & 81 & 80,2 & 82 & 95,3 \\
\hline \multicolumn{5}{|l|}{ Kelompok umur } \\
\hline$<45$ tahun & 17 & 16,8 & 9 & 10,4 \\
\hline$\geq 45$ tahun & 84 & 83,2 & 77 & 89,6 \\
\hline \multicolumn{5}{|l|}{ Pendidikan } \\
\hline Rendah & 42 & 41,6 & 63 & 73,3 \\
\hline Menengah & 48 & 47,5 & 22 & 25,6 \\
\hline Tinggi & 11 & 10,9 & 1 & 1,2 \\
\hline \multicolumn{5}{|l|}{ Pekerjaan } \\
\hline Tidak bekerja & 14 & 13,9 & 6 & 7,0 \\
\hline Ibu Rumah Tangga & 61 & 60,4 & 58 & 67,4 \\
\hline PNS/BUMN & 1 & 1,0 & 0 & 0,0 \\
\hline Pegawai Swasta & 3 & 3,0 & 0 & 0,0 \\
\hline Wiraswasta/Pedagang & 6 & 5,9 & 13 & 15,1 \\
\hline Petani/ nelayan/buruh/ sopir & 5 & 5,0 & 6 & 7,0 \\
\hline Lainnya & 11 & 10,9 & 3 & 3,5 \\
\hline \multicolumn{5}{|l|}{ Status Kawin } \\
\hline Belum kawin & 1 & 1,0 & 0 & 0,0 \\
\hline Kawin & 71 & 70,3 & 68 & 79,1 \\
\hline Cerai Hidup & 4 & 4,0 & 1 & 1,2 \\
\hline Cerai Mati & 25 & 24,8 & 17 & 19,8 \\
\hline
\end{tabular}


Posbindu..., iya kadang-kadang remaja itu merasa ah, dia sehat, badannya. Dia kuat kan. Jadi dia maksudnya eee, dianggap entenglah istilahnya, penyakit itu. (FGD kader Posbindu).

Responden yang berkunjung ke Posbindu di Kabupaten Cirebon sebagian besar berpendidikan rendah (73,3\%). Responden di Kota Cimahi sebagian besar responden berpendidikan sedang $(47,5 \%)$.

Dari Tabel 1 tampak bahwa di kedua kota/ kabupaten sebagian besar pengunjung Posbindu adalah ibu rumah tangga. Di kota Cimahi pengunjung juga didominasi ibu rumah tangga $(60,4 \%)$ dan di urutan kedua tidak bekerja (13,9\%). Tidak berbeda jauh di Kabupaten Cirebon terbanyak juga ibu rumah tangga $(67,4 \%)$ dan disusul wiraswasta/pedagang $(15,1 \%)$. Berdasarkan status perkawinan, persentase responden yang kawin lebih banyak berkunjung ke Posbindu PTM.

Program Posbindu PTM mulai dilaksanakan pada tahun 2011. Posbindu PTM mulai pertama kali dilaksanakan di Kota Cimahi Tahun 2011. Pelaksanaan ini sesuai dengan program pemerintah. Namun demikian proporsi kunjungan tertinggi pada tahun 2014 (35,6\%). Pelaksanaan Posbindu PTM di Kabupaten Cirebon, mulai dilaksanakan tahun 2012. Proporsi kunjungan terbanyak pada 2013 $(62,8 \%)$. Berdasarkan frekuensi responden yang memanfaatkan Posbindu terbanyak sebesar 9-12 kali kunjungan dengan rerata 10 kali kunjungan di Kota Cimahi maupun Kabupaten Cirebon.

\section{Pelaksanaan Posbindu PTM}

Penelitian dilakukan di 10 Posbindu PTM di Kota Cimahi dan Kabupaten Cirebon. Posbindu PTM yang mulai dilaksanakannya sesuai dengan program (tahun 2011) hanya satu Posbindu, di Kota Cimahi. Hampir semua Posbindu PTM melaksanakan kegiatan Posbindu rutin setiap bulan dalam 12 bulan terakhir. Hal ini sesuai dengan informasi yang diperoleh dari FGD penanggungjawab Posbindu PTM yang mengatakan..

"Di Cigugur kita ngga ada gabungan dengan Posyandu. Kebetulan PTMnya, paling gabung dengan yang lansianya, rutin tiap bulan, ada jadwalnya." (PJ Posbindu PTM Kota Cimahi)

Demikian pula seperti yang diinformasikan oleh kader...

"dilaksanakan setiap selasa pertama tiap bulan, mungkin saya gak pake undangan, kalau pertemuan di PKK suka diumumin. Terus waktu hari $H$ diumumkan di masjid-masjid setiap bulan mulai jam 9 sampai selesai." (Kader Cimahi)

Berdasarkan tempat pelaksanaannya, Posbindu umumnya belum menggunakan bangunan khusus Posbindu PTM. Biasanya pelaksanaannya di rumah penduduk, Balai desa/balai serbaguna/ Gedung Balai pertemuan kampung (Baperkam)/ Gedung Swadaya masyarakat. Hanya 1 Posbindu PTM di Kabupaten Cirebon yang sudah punya bangunan khusus Posbindu PTM.

Tempat pelaksanaan Posbindu PTM bisa di mana saja, seperti yang disampaikan oleh informan saat wawancara mendalam..

"Tempat pelaksanaan Posbindu bisa di mana saja., di tempat kerja, kantor, di sekolah". (Dinkes)."

"Rutin datang karena diadakan di rumah saya sendiri." (Tokoh masyarakat).

Pada Tabel 2 menunjukkan sebagian besar responden datang ke Posbindu PTM dengan alasan untuk pengukuran tekanan darah yaitu di Kota Cimahi 85,1\% responden untuk pengukuran tekanan darah dan 74,3\% untuk cek kesehatan. Sementara di Kabupaten Cirebon 83,7\% untuk cek kesehatan dan $66,3 \%$ untuk pengukuran tekanan darah. Tujuan lainnya reponden datang ke Posbindu adalah ingin berobat $(10,9 \%)$ pemeriksaan asam urat $(4 \%)$ informasi kesehatan $(1,4 \%)$ dan lainnya. Hal ini senada dengan yang disampaikan oleh informan.

"Tujuannya mereka datang sih tensi tadi itu bu, kan mereka ga begitu paham itu, paling mereka rutinitas tensi, kaya, gitu." (Kader Posbindu PTM Cimahi)

Demikian pula yang disampaikan oleh informan tentang tujuan masyarakat datang ke Posbindu PTM...

"Tujuannya ingin ditensi, ditimbang, konseling, dapat bertanya makan sayur berapa porsi dan olahraga." (Tokoh masyarakat Kota Cimahi)

Terkait dengan kegiatan pengukuran dan pemeriksaan yang dilakukan di Posbindu PTM sebagian besar responden mengatakan sudah sesuai dengan harapan yaitu di Kota Cimahi $82,2 \%$ dan Kabupaten Cirebon 98,8\%. Sedangkan responden yang menjawab belum sesuai, sebagian besar responden mengharapkan agar di Posbindu PTM ada 
Tabel 2. Kegiatan Posbindu PTM di Provinsi Jawa Barat

\begin{tabular}{|c|c|c|c|c|}
\hline \multirow{2}{*}{ Variabel } & \multicolumn{2}{|c|}{ Kota Cimahi } & \multicolumn{2}{|c|}{ Kab. Cirebon } \\
\hline & $\mathbf{N}$ & $\%$ & $\mathbf{n}$ & $\%$ \\
\hline \multicolumn{5}{|l|}{ Tahun pertama kali ke Posbindu PTM } \\
\hline 2011 & 8 & 7,9 & 0 & 0,0 \\
\hline 2012 & 28 & 27,7 & 8 & 9,3 \\
\hline 2013 & 16 & 15,8 & 54 & 62,8 \\
\hline 2014 & 36 & 35,6 & 19 & 22,1 \\
\hline 2015 (Januari sd Agustus 2015) & 13 & 12,9 & 5 & 5,8 \\
\hline \multicolumn{5}{|l|}{ Frekuensi kunjungan ke Posbindu PTM } \\
\hline$\leq 4$ & 10 & 9,9 & 5 & 5,8 \\
\hline $5-8$ & 21 & 20,8 & 20 & 23,3 \\
\hline $9-12$ & 70 & 69,3 & 61 & 70,9 \\
\hline Kisaran & $2-12$ & & $3-12$ & \\
\hline Rerata & 10 & & 10 & \\
\hline \multicolumn{5}{|l|}{ Tujuan datang ke Posbindu PTM } \\
\hline Pengukuran TB & 67 & 66,3 & 31 & 36,0 \\
\hline Pengukuran BB & 74 & 73,3 & 38 & 44,2 \\
\hline Pengukuran Lingkar perut & 66 & 65,3 & 34 & 39,5 \\
\hline Pengukuran TD & 86 & 85,1 & 57 & 66,3 \\
\hline Pemeriksaan kolesterol & 18 & 17,8 & 7 & 8,1 \\
\hline Pemeriksaan gula darah & 16 & 15,8 & 13 & 15,1 \\
\hline Konseling & 46 & 45,5 & 27 & 31,4 \\
\hline Cek Kesehatan & 75 & 74,3 & 72 & 83,7 \\
\hline Lainnya & 14 & 13,9 & 15 & 17,4 \\
\hline \multicolumn{5}{|l|}{ Iuran/retribusi } \\
\hline Sukarela & 51 & 50,5 & 0 & 0,0 \\
\hline Tidak & 50 & 49,5 & 86 & 100,0 \\
\hline \multicolumn{5}{|l|}{ Jumlah kader } \\
\hline$<5$ & 5 & 4,0 & 8 & 9,3 \\
\hline$\geq 5$ & 96 & 95,0 & 78 & 90,7 \\
\hline \multicolumn{5}{|l|}{ Pelaksanaan Posbindu setiap bulan } \\
\hline Ya & 99 & 98,0 & 84 & 97,7 \\
\hline Tidak & 0 & 0,0 & 0 & 0,0 \\
\hline Tidak tahu & 2 & 2,0 & 2 & 2,3 \\
\hline \multicolumn{5}{|l|}{ Posbindu mudah dijangkau } \\
\hline $\mathrm{Ya}$ & 100 & 99,0 & 86 & 100,0 \\
\hline Tidak & 1 & 1,0 & 0 & 0,0 \\
\hline \multicolumn{5}{|l|}{ Ada pemeriksaan darah } \\
\hline Ya & 13 & 12,9 & 51 & 59,3 \\
\hline Tidak & 88 & 87,1 & 35 & 40,7 \\
\hline
\end{tabular}


pemeriksaan darah seperti gula darah, kolesterol, asam urat dan memberikan pengobatan.

Lebih dari $90 \%$ responden di semua tempat melaporkan bahwa kegiatan Posbindu PTM selalu dilaksanakan setiap bulan, tempat kegiatan Posbindu juga mudah dijangkau dari tempat tinggal responden dan setiap datang ke Posbindu PTM, responden selalu mendaftar terlebih dahulu.

Tabel 3 menunjukkan bahwa di Kota Cimahi banyak responden yang menjawab tidak ada pemeriksaan darah di Posbindu PTM (87,1\%).
Hal ini sesuai dengan yang diungkapkan kader saat FGD.

"Belum ada tapi untuk lab pengen bisa periksa darah." (Kader Posbindu).

Responden di Kabupaten Cirebon lebih banyak yang menjawab ada pemeriksaan darah di Posbindu PTM (59,3\%). Dari seluruh responden yang mengetahui ada pemeriksaan darah di Posbindu PTM sebagian besar telah mengetahui jenis pemeriksaan yang dilakukan di Posbindu PTM, terendah Kota Cimahi (69,2\%). Pada Tabel 3 menunjukkan bahwa

\section{Tabel 3. Kegiatan Pemeriksaan Darah di Posbindu PTM di Provinsi Jawa Barat}

\begin{tabular}{|c|c|c|c|c|}
\hline \multirow{3}{*}{ Pemeriksaan darah } & \multicolumn{4}{|c|}{ Jawa Barat } \\
\hline & \multicolumn{2}{|c|}{ Kota Cimahi } & \multicolumn{2}{|c|}{ Kabupaten Cirebon } \\
\hline & $\mathbf{n}$ & $\%$ & n & $\%$ \\
\hline \multicolumn{5}{|l|}{ Mengetahui pemeriksaan darah } \\
\hline $\mathrm{Ya}$ & 9 & 69,2 & 41 & 80,4 \\
\hline Tidak & 4 & 30,8 & 10 & 19,6 \\
\hline \multicolumn{5}{|l|}{ Frekuensi pemeriksaan gula darah } \\
\hline 0 & 1 & 11,1 & 19 & 46,3 \\
\hline $1-4$ & 5 & 55,6 & 15 & 36,6 \\
\hline $5-8$ & 1 & 11,1 & 4 & 9,8 \\
\hline $9-12$ & 2 & 22,2 & 3 & 7,3 \\
\hline \multicolumn{5}{|c|}{ Petugas memberikan Informasi hasil pemeriksaan gula darah } \\
\hline Normal & 6 & 75,0 & 14 & 63,6 \\
\hline Tidak normal & 2 & 25,0 & 8 & 36,4 \\
\hline Tidak diinformasikan & 0 & 0,0 & 0 & 0,0 \\
\hline \multicolumn{5}{|l|}{ Dikenakan biaya pemeriksaan gula darah } \\
\hline Ya & 9 & 100,0 & 27 & 65,9 \\
\hline Tidak & 0 & 0,0 & 12 & 29,3 \\
\hline Tidak tahu & 0 & 0,0 & 2 & 4,9 \\
\hline \multicolumn{5}{|l|}{ Biaya pemeriksaan gula darah } \\
\hline$<\operatorname{Rp} 5.000$ & 0 & 0,0 & 0 & 0,0 \\
\hline$\geq$ Rp5.000 & 9 & 100,0 & 26 & 89,7 \\
\hline Tidak tahu & 0 & 0,0 & 3 & 10,3 \\
\hline \multicolumn{5}{|l|}{ Frekuensi pemeriksaan kolesterol } \\
\hline 0 & 2 & 22,2 & 31 & 77,5 \\
\hline $1-4$ & 6 & 66,7 & 8 & 20,0 \\
\hline $5-8$ & 1 & 11,1 & 0 & 0,0 \\
\hline $9-12$ & 0 & 0,0 & 1 & 2,5 \\
\hline \multicolumn{5}{|c|}{ Petugas memberikan Informasi hasil pemeriksaan kolesterol } \\
\hline Normal & 3 & 42,9 & 6 & 66,7 \\
\hline Tidak normal & 4 & 57,1 & 2 & 22,2 \\
\hline Tidak diinformasikan & 0 & 0,0 & 1 & 11,1 \\
\hline
\end{tabular}




\begin{tabular}{|c|c|c|c|c|}
\hline \multirow{3}{*}{ Pemeriksaan darah } & \multicolumn{4}{|c|}{ Jawa Barat } \\
\hline & \multicolumn{2}{|c|}{ Kota Cimahi } & \multicolumn{2}{|c|}{ Kabupaten Cirebon } \\
\hline & n & $\%$ & $\mathbf{n}$ & $\%$ \\
\hline \multicolumn{5}{|l|}{ Dikenakan biaya pemeriksaan kolesterol } \\
\hline Ya & 6 & 85,7 & 5 & 55,6 \\
\hline Tidak & 1 & 14,3 & 4 & 44,4 \\
\hline \multicolumn{5}{|l|}{ Biaya pemeriksaan kolesterol } \\
\hline$<\mathrm{Rp} 5.000$ & 0 & 0,0 & 0 & 0,0 \\
\hline$\geq \operatorname{Rp} 5.000$ & 6 & 100,0 & 5 & 100,0 \\
\hline \multicolumn{5}{|c|}{$\begin{array}{l}\text { Petugas menyarankan puasa minimal } 10 \text { jam sebelum } \\
\text { pemeriksaan darah }\end{array}$} \\
\hline $\mathrm{Ya}$ & 6 & 60,0 & 3 & 7,3 \\
\hline Tidak & 3 & 30,0 & 37 & 90,2 \\
\hline Kadang-kadang & 0 & 0,0 & 1 & 2,4 \\
\hline \multicolumn{5}{|l|}{ Yang melakukan pemeriksaan darah } \\
\hline Dokter & 0 & 0,0 & 0 & 0,0 \\
\hline Petugas kesehatan & 0 & 0,0 & 48 & 94,1 \\
\hline Kader & 13 & 100 & 2 & 3,9 \\
\hline Tidak Tahu & 0 & 0,0 & 1 & 2,0 \\
\hline \multicolumn{5}{|l|}{ Saran dari petugas Posbindu PTM } \\
\hline Kunjungan ulang & 43 & 42,6 & 42 & 48,8 \\
\hline Dirujuk ke Puskesmas & 3 & 3,0 & 5 & 5,8 \\
\hline Diet & 58 & 57,4 & 62 & 72,1 \\
\hline Dijelaskan dampak/ risiko penyakit & 12 & 11,9 & 28 & 32,6 \\
\hline Olahraga & 46 & 45,5 & 45 & 52,3 \\
\hline Tidak ada saran & 12 & 11,9 & 21 & 24,4 \\
\hline
\end{tabular}

sebagian besar responden memeriksakan kadar gula darah sebanyak satu sampai empat kali dalam 12 bulan terakhir. Semua responden mendapatkan informasi hasil pemeriksaan darah dari petugas.

Banyak responden di Kabupaten Cirebon yang tidak melakukan pemeriksaan kolesterol darah dalam 12 bulan terakhir (77,5\%). Sedangkan di Kota Cimahi responden yang melakukan pemeriksaan kolesterol dengan frekuensi 1-4 kali dalam 12 bulan terakhir sebesar $57,1 \%$ dan $66,7 \%$. Sebagian besar responden mendapatkan informasi hasil pemeriksaan kolesterol darahnya. Namun masih ada responden yang tidak diinformasikan hasil pemeriksaan darahnya di Kabupaten Cirebon. Seluruh responden di Provinsi Jawa Barat diperiksa kolesterol darahnya dipungut biaya sebesar Rp.5.000 atau lebih. Biaya pemeriksaan gula darah dan kolesterol bervariasi, seperti yang diungkapkan oleh tokoh masyarakat saat wawancara mendalam.

"Gratis kecuali kalau periksa darah cholesterol Rp 25.000 dan gula darah Rp 20.000.” (Tokoh masyarakat).

Responden di Kota Cimahi sebagian besar disarankan berpuasa minimal 10 jam sebelum pemeriksaan darah $(60 \%)$ sebaliknya sebagian besar responden di Kabupaten Cirebon tidak disarankan $(80,5)$. Hanya Kota Cimahi yang respondennya mengatakan bahwa yang melakukan pemeriksaan darah di Posbindu PTM seluruhnya dilakukan oleh kader (100\%). Sedangkan responden di Kabupaten Cirebon mengatakan bahwa hampir $100 \%$ pemeriksaan darah dilakukan oleh petugas kesehatan.

Saran yang paling banyak diberikan oleh 
petugas Posbindu PTM kepada responden adalah agar melakukan perbaikan pola makan/diet, berolah raga dan melakukan kunjungan ulang ke Posbindu PTM.

Pada Tabel 4. Kegiatan rujukan telah dilaksanakan di Posbindu PTM tetapi tidak semua responden yang dirujuk, diberikan surat rujukan. Lebih dari $50 \%$ responden yang dirujuk mendatangi Puskesmas rujukan. Hal ini sesuai dengan yang diungkapkan oleh informan saat FGD.

"Dalam hal mengajak masyarakat berpartisipasi dan merujuk pengunjung ke Puskesmas. Pengunjung berharap dapat obat di Posbindu." (Kader Posbindu PTM).

\section{Sumber Daya Manusia}

Berdasarkan ketersediaan sumber daya manusia diperoleh informasi bahwa seluruh SDM yang terlibat dalam Posbindu belum seluruhnya mendapatkan pelatihan Posbindu PTM. SDM yang telah mendapatkan pelatihan Posbindu PTM adalah pemegang program PTM, petugas kesehatan dan sebagian besar kader. Hal ini dikarenakan tingginya komitmen dari pemerintah dalam menjalankan program Posbindu PTM. Berdasarkan telaah dokumen dan observasi pada Dinas kesehatan dan Puskesmas ditemukan bukti kegiatan pengadaan pelatihan untuk kader, sertifikat pelatihan yang dimiliki oleh kader Posbindu. Sedangkan hasil FGD dengan kelompok kader Posbindu diperoleh informasi berbeda bahwa masih ada kader yang belum mendapatkan pelatihan Posbindu PTM.

Kader Posbindu PTM adalah seorang tenaga sukarela yang direkrut dari, oleh dan untuk masyarakat, yang mau dan sanggup melaksanakan kegiatan Posbindu PTM, serta mau dan sanggup menggerakkan masyarakat untuk melaksanakan dan mengikuti kegiatan Posbindu PTM. Kader terlatih adalah kader Posbindu PTM yang sudah mendapatkan pelatihan Posbindu PTM.

Jumlah kader Posbindu sudah sesuai dengan juknis yaitu minimal 5 orang kader. Sebagian besar responden mengatakan bahwa jumlah kader Posbindu PTM lebih dari 5 orang dengan ratarata jumlah kader di Kota Cimahi 9 orang dan Kabupaten Cirebon 6 orang. Hal ini senada dengan yag diungkapkan oleh informan saat FGD ...

"sesuai yang dilatih kan ada 5, tapi kenyataan pada pelaksanaan ya kadang-kadang banyak yang membantu. Makanya mejanya itu ada 5 ada 8, saking banyaknya". (FGD PJ Posbindu).

Berdasarkan informasi dari informan bahwa kader telah melaksanakan tugasnya sesuai dengan tugas pokok yang terdapat dalam kebijakan juknis. Tugas kader yaitu mengingatkan jadwal dan mengajak masyarakat memeriksakan diri ke Posbindu PTM, menyiapkan tempat dan perlengkapan Posbindu. Sesuai hasil observasi, tugas kader ketika ada masyarakat yang hadir ke Posbindu yaitu melakukan pencatatan, menimbang berat badan, mengukur tensi, mengukur lingkar perut dan memberikan penyuluhan. Selain itu di beberapa Posbindu PTM kader mempersiapkan makanan tambahan untuk masyarakat yang hadir.

\section{Pendanaan}

Berdasarkan penjelasan informan, pembiayaan program Posbindu PTM di Kota Cimahi dan Kabupaten Cirebon didapatkan dari berbagai sumber dana. Buku pedoman pelaksanaan, Posbindu kit selain didapat dari Kementerian Kesehatan juga berasal dari dana APBD dan swadaya. Sumber dana yang digunakan untuk pelaksanaan Posbindu PTM selain berasal dari dana operasional yang diberikan

Tabel 4. Pelaksanaan Rujukan di Posbindu PTM Provinsi Jawa Barat

\begin{tabular}{|c|c|c|c|c|}
\hline \multirow[t]{2}{*}{ Variabel } & \multicolumn{2}{|c|}{ Kota Cimahi } & \multicolumn{2}{|c|}{ Kab. Cirebon } \\
\hline & $\mathbf{n}$ & $\%$ & $\mathbf{n}$ & $\%$ \\
\hline \multicolumn{5}{|l|}{ Diberikan surat rujukan } \\
\hline $\mathrm{Ya}$ & 2 & 66,7 & 2 & 40,0 \\
\hline Tidak & 1 & 33,3 & 3 & 60,0 \\
\hline \multicolumn{5}{|l|}{ Datang ke Puskesmas sesuai dengan rujukan } \\
\hline $\mathrm{Ya}$ & 2 & 66,7 & 3 & 60,0 \\
\hline Tidak & 1 & 33,3 & 2 & 40,0 \\
\hline
\end{tabular}


oleh Dinas kesehatan setiap tiga bulan sekali, ada juga sebagian besar yang memanfaatkan dana kencleng yang dikumpulkan warga secara sukarela pada setiap datang ke Posbindu. Biaya operasional untuk kegiatan Posbindu PTM yang dikeluarkan berkisar antara 50 ribu sampai 100 ribu rupiah. Pada umumnya biaya tersebut digunakan untuk keperluan fotokopi dan konsumsi tetapi beberapa hanya cukup untuk fotokopi saja. Dalam pelaksanaannya, tidak ada satu pun Posbindu PTM yang menetapkan iuran wajib kepada pengunjung. Iuran yang ada bersifat sukarela seperti Kota Cimahi, namun di Kabupaten Cirebon tidak ada iuran sukarela. Hal serupa disampaikan pada FGD sebagai berikut...

"Ga pernah kita minta bayaran. Kecuali yang periksa aja. Iurannya gratis semua." (Kader Posbindu).

"Bergabung dengan posyandu lansia, ada dana dari PKM per tiga bulan (47 ribu) kemudian dana dari kencleng" (Kader Posbindu)

\section{Sarana dan Prasarana}

Sarana prasarana diperoleh informasi bahwa belum semua Posbindu PTM yang berada di wilayah kerja Puskesmas mempunyai Posbindu kit masing-masing, sehingga penggunaannya harus bergantian pada waktu pelaksanaan. Posbindu kit berisikan tensi meter, alat pengukur berat badan, alat pengukur lingkar lengan atas, alat pengukur lingkar perut, peakflow meter, buku petunjuk teknis Posbindu PTM. Namun demikian deteksi dini PPOK masih belum dapat dijalankan walaupun alat peakflow meter tersedia karena kader merasa belum dilatih. Sebagian Posbindu PTM dilengkapi dengan alat pemeriksa gula darah, kolesterol, dan asam urat.

Berdasarkan hasil FGD kelompok kader diketahui bahwa hampir seluruh dari informan memberikan informasi bahwa media KIE tidak ada di Posbindu seperti poster, leaflet, lembar balik untuk konseling dan ada sebagian peralatan yang digunakan di Posbindu mengalami kerusakan. Buku petunjuk teknis yang digunakan sebagai pedoman pelaksanaan Posbindu PTM di lapangan dikeluarkan oleh Kementerian Kesehatan Direktorat Penyakit Tidak Menular dan telah terdistribusi seluruhnya dari Dinas kesehatan ke Puskesmas dan seterusnya ke penanggung jawab dan petugas pelaksana Posbindu.
Pelaksanaan telah berjalan sesuai juknis SOP yang ada. Pelaksanaan sistem 5 meja meliputi Isi form pendataan, pengukuran tinggi badan, timbang berat badan, pencatatan selanjutnya ke tim medis tensi, cek pemeriksaan darah, pemberian konsultasi oleh kader/petugas. Kualitas pelayanan pada umumnya sudah baik namun ada beberapa hal dirasakan masih kurang maksimal dalam pelayanan di mana masyarakat masih merasa kurang puas karena alat pemeriksaan tidak cukup dan sering rusak serta pelaksanaan Posbindu diadakan pada jam kerja. Kepala Dinas Kesehatan agar melengkapi Posbindu PTM kit dan memperbaiki sarana prasarana yang rusak.

\section{Pembahasan}

Posbindu PTM merupakan wujud peran serta masyarakat dalam melakukan kegiatan deteksi dini dan monitoring faktor risiko PTM yang dilaksanakan secara terpadu, rutin dan periodik. Target dan sasaran Posbindu PTM adalah laki-laki dan perempuan berusia 15 tahun ke atas. Kegiatan Posbindu PTM diharapkan dapat meningkatkan sikap mawas diri masyarakat terhadap faktor risiko PTM sehingga kejadian kasus PTM dapat dicegah.

Kader sebagai sukarelawan dan perantara upaya peningkatan kesehatan masyarakat perlu mendapat dukungan dari Kementerian Kesehatan. ${ }^{8}$ Begitu juga dengan dukungan peran kader dalam keberlangsungan program Posbindu PTM yang perlu mendapatkan perhatian dari Kementerian Kesehatan. Permenkes Nomor 65 Tahun 2013 Tentang Pedoman Pelaksanaan dan Pembinaan Pemberdayaan Masyarakat Bidang Kesehatan Bab III menyebutkan "peningkatan keberdayaan masyarakat berarti peningkatan kemampuan dan kemandirian masyarakat agar dapat mengembangkan diri untuk mencapai derajat kesehatan yang lebih baik". ${ }^{\circ}$ Berdasarkan hasil penelitian ini menunjukkan bahwa tugas kader Posbindu PTM dalam pelaksanaan program pengendalian PTM yang dilakukan di Posbindu sudah sesuai dengan pedoman teknis Posbindu PTM. ${ }^{4}$ Hal ini sesuai dengan temuan Nugraheni pada penelitiannya di Posbindu di Kota Bogor tahun 2017. ${ }^{10}$

Penelitian ini menunjukkan bahwa Posbindu dilaksanakan secara rutin tiap bulannya. Sebagian besar responden yang berkunjung ke Posbindu PTM 
adalah perempuan dan lebih dari $60 \%$ adalah ibu rumah tangga. Hal ini sesuai dengan hasil penelitian Sunartyasih di Bandung sebagian besar pengunjung Posbindu PTM adalah perempuan. ${ }^{11}$

Pemanfaatan Posbindu PTM usia 15-44 tahun sangat rendah, sebagian besar responden yang berkunjung ke Posbindu PTM berumur 45 tahun keatas mencapai $86 \%$. Hasil ini sesuai dengan hasil penelitian Fauzia di Kota Bogor yang menyatakan bahwa pemanfaatan Posbindu PTM usia 18-44 tahun rendah. ${ }^{12}$

Pemanfaatan Posbindu PTM yang rendah mungkin disebabkan oleh motivasi masyarakat yang kurang untuk hadir ke Posbindu PTM. Menurut Purwanto, motivasi adalah semua penggerak, alasan-alasan atau dorongan dalam diri manusia yang menyebabkan seseorang berbuat sesuatu. ${ }^{13}$ Motivasi itu timbul karena adanya suatu kebutuhan atau keinginan yang harus dipenuhi. Keinginan itu akan mendorong individu untuk melakukan suatu tindakan, agar tujuannya tercapai. Menurut Sunaryo, motivasi adalah dorongan penggerak untuk mencapai tujuan tertentu, baik disadari maupun tidak disadari. ${ }^{14}$ Motivasi dapat timbul dari dalam diri individu atau datang dari lingkungan. Masyarakat yang tidak datang ke Posbindu PTM dapat disebabkan karena mereka sekolah, bekerja ataupun karena sedang tidak ada di rumah. Sehingga pelaksanaan Posbindu PTM di lokasi penelitian belum sepenuhnya dimanfaatkan oleh masyarakat usia produktif.

Pelaksanaan Posbindu pada hari kerja dan pagi hari menyebabkan sasaran yang datang lebih banyak perempuan, umur 45 tahun keatas. Hal ini disebabkan pada hari dan waktu tersebut laki-laki sedang melaksanakan tugasnya mencari nafkah (bekerja). Sebagai ibu rumah tangga memiliki waktu lebih banyak dibandingkan lakilaki yang harus bekerja di luar rumah sebagai kepala keluarga. ${ }^{15}$ Dalam anggapan budaya di Indonesia, perempuan punya kewajiban mengurus rumah tangga, sementara mencari nafkah dilakukan suami. ${ }^{16}$ Sementara itu bagi yang berumur 15 tahun sampai 44 tahun, ada yang sekolah, atau kuliah sehingga tidak dapat datang ke Posbindu PTM. Selain itu, kesadaran masyarakat umur $<45$ tahun masih rendah untuk melakukan deteksi dini PTM. Pada usia remaja sebetulnya sebagian besar dari mereka memahami permasalahan kesehatan, hanya saja, populasi remaja enggan untuk memeriksakan kesehatannya. ${ }^{17}$ Beberapa remaja mungkin merasa malu atau merasa terintimidasi bila bertemu dengan dokter. ${ }^{18}$ Berdasarkan hasil penelitian Kurnia di Pemalang diketahui bahwa responden pada usia produktif menyatakan tidak melakukan kunjungan secara rutin karena sibuk bekerja sehingga tidak sempat datang rutin dan menyatakan bahwa datang ke Posbindu PTM secara rutin menyita waktu. ${ }^{19}$

Perlu dilakukan penyesuaian pelaksanaan Posbindu PTM dengan karakteristik masing-masing daerah agar cakupan masyarakat yang datang ke Posbindu PTM lebih tinggi. Misalnya Posbindu PTM dapat dilakukan di hari libur kerja (Sabtu atau Minggu) atau setelah jam kerja (jam 16.00 WIB ke atas) sehingga dapat menjaring laki-laki, perempuan dan anak sekolah. Cara lain untuk menjaring subyek yang berumur muda adalah dengan mengintegrasikan kegiatan Posbindu PTM dengan Upaya Kesehatan Sekolah (UKS).

Pelaksanaan Posbindu PTM sudah sesuai dengan pedoman yang dikeluarkan oleh Direktorat Jendral Pengendalian Penyakit dan Penyehatan Lingkungan (P2PL) Kementerian Kesehatan RI. Mereka sudah melaksanakan sistem 5 meja: pendaftaran/registrasi, wawancara faktor risiko oleh petugas pelaksana Posbindu PTM, pengukuran (berat badan, tinggi badan, IMT dan lingkar perut), pemeriksaan tekanan darah, konseling/edukasi serta tindak lanjut. ${ }^{20}$ Bahkan ada Posbindu yang swadaya melaksanakan pemeriksaan gula darah. Kader yang bertugas berjumlah 5-12 orang dengan pembagian tugas sesuai kemampuan masingmasing. Pelaksanaan Posbindu PTM di beberapa Posbindu digabung dengan pelaksanaan Posbindu lansia maupun Posbindu untuk meningkatkan cakupan masyarakat yang datang ke Posbindu PTM. Pelaporan hasil pelaksanaan Posbindu PTM dilakukan setelah usai kegiatan secara rutin ke Dinas Kesehatan setempat. Buku pedoman pelaksanaan, Posbindu kit selain didapat dari pusat juga berasal dari dana APBD dan swadaya. Dana swadaya berasal dari donatur RW dan kencleng yang dikumpulkan warga secara sukarela pada setiap datang ke Posbindu PTM. Dana operasional Posbindu berasal dari APBD.

Dasar penyelenggaraan Posbindu adalah 
SK Dinas Kesehatan dan SK Puskesmas sebagai pengelola Posbindu. Bahkan untuk kader ada SK dari kelurahan. Warga masyarakat yang datang ke Posbindu PTM di kedua provinsi tersebut sebagian besar merasa puas terhadap semua aspek penilaian pelaksanaan Posbindu, baik dari segi kemampuan dan keterampilan petugas, keramahan petugas, waktu penyelenggaraan (tidak mengganggu kesibukan responden), ketepatan waktu, kecepatan pelayanan, kebersihan dan kenyamanan Posbindu.

Faktor pendukung dalam pelaksanaan program Posbindu PTM adalah adanya buku pedoman Posbindu PTM, adanya Posbindu kit, adanya kader yang mampu mengidentifikasi faktor risiko PTM dan adanya kesiapan tenaga medis/ paramedis dalam penanganan PTM serta adanya dukungan dari kepala Dinas kesehatan dalam menangani PTM dengan adanya SK bagi petugas pelaksana Posbindu PTM.

Sedangkan faktor penghambatnya adalah waktu penyelenggaraan Posbindu di hari kerja dan pagi hari, masyarakat tidak mau ke Posbindu PTM bila tidak ada pengobatan, penyuluhan yang diberikan oleh kader kurang lengkap, kurangnya dukungan dari perangkat desa, dan keterbatasan tenaga medis/paramedis dan seringnya terjadi pergantian kader Posbindu PTM.

Hasil dalam penelitian ini tidak berbeda jauh dengan temuan yang didapatkan oleh Putri dkk. Posbindu PTM di Wilayah Puskesmas Simpang Sungai Duren juga telah melaksanakan pelayanan sistem lima meja. Namun demikian terdapat beberapa kendala dalam implementasinya seperti belum memiliki tempat khusus pelaksanaan Posbindu PTM, peran kader belum optimal, kurangnya jumlah kader, minimnya sumber dana, kurangnya koordinasi hasil kegiatan dengan pemangku kepentingan. ${ }^{21}$

Waktu penyelenggaraan Posbindu dapat disesuaikan dengan karakteristik masyarakat pada daerah masing-masing atau disinkronkan dengan kegiatan lainnya seperti posyandu atau UKS. Perlu juga disediakan obat-obatan esensial untuk penanganan penyakit kronis untuk meningkatkan cakupan warga yang datang ke Posbindu PTM. Untuk menjaga kesinambungan pengetahuan tentang Posbindu PTM, perlu dilakukan refresh training bagi kader terutama kader yang sering berganti dan tenaga kesehatan. Perlu peningkatan kerjasama dengan dokter/bidan praktek swasta terdekat dengan lokasi Posbindu atau bahkan dengan CSR perusahaan untuk meningkatkan kualitas pelayanan di Posbindu PTM. Dengan demikian diharapkan Posbindu dapat dilaksanakan dengan lebih baik, cakupannya meningkat dan pada akhirnya dapat mengurangi angka kesakitan dari penyakit tidak menular.

\section{Kesimpulan}

Pelaksanaan program Posbindu PTM di Kota Cimahi dan Kabupaten Cirebon dikunjungi oleh sebagian besar perempuan dan berusia di atas 45 tahun. Kapasitas kader dan pendanaan Posbindu PTM perlu ditingkatkan serta Posbindu kit dilengkapi untuk setiap Posbindu PTM.

\section{Saran}

Alternatif strategi yang dapat dilakukan untuk menarik minat warga untuk memanfaatkan Posbindu PTM adalah adanya pemeriksaan gula darah, kolesterol dan asam urat secara gratis, penyesuaian waktu pelaksanaan Posbindu sehingga pengunjung laki-laki dapat memanfaatkan Posbindu serta pelatihan kader perlu diintensifkan.

\section{Daftar Rujukan}

1. Kementerian kesehatan RI. 2012. Penyakit tidak menular. Vol. 2, Buletin jendela data dan informasi kesehatan. [Di akses pada 10 Juli 2019]

2. Kemenkes RI. Petunjuk teknis pos pembinaan terpadu penyakit tidak menular (Posbindu ptm). Jakarta:Direktorat Pengendalian Penyakit dan Penyehatan Lingkungan; 2012 [diakses pada 18 Februari 2020.]. Tersedia pada: http://p2ptm. kemkes.go.id/uploads/2016/10/PetunjukTeknis-Pos-Pembinaan-Terpadu-PenyakitTidak-Menular-POSBINDU-PTM.pdf

3. Kemenkes RI. Petunjuk teknis pos pembinaan terpadu penyakit tidak menular (Posbindu ptm). Jakarta:Direktorat Pengendalian Penyakit dan Penyehatan Lingkungan; 2014 [diakses pada 18 Februari 2020]. Tersedia pada: http://p2ptm. kemkes.go.id/uploads/2016/10/PedomanUmum-Pos-Pembinaan-Terpadu-PenyakitTidak-Menular.pdf 
4. Kementerian Kesehatan RI. Pedoman teknis penelusuran dan tatalaksana hipertensi. Jakarta: Direktorat Pengendalian Penyakit Tidak Menular [Internet]; 2013 [diakses pada 19 Februari 2020]. Tersedia pada: http://p2ptm. kemkes.go.id/dokumen-p2ptm/pedomanteknis-penemuan-dan-tatalaksana-hipertensi

5. World Health Organization. 2011. Fact Sheet: Hypertension [Internet]. WHO Regional Office for South-East Asia Region .; September 2011 [diakses pada 18 Februari 2020]. Tersedia pada:http://origin.searo.who.int/entity/ noncommunicable_diseases/media/non communicable_diseases_hypertension_fs.pdf

6. Kementerian Kesehatan RI. Laporan Nasional Riset Kesehatan Dasar 2013. Jakarta: Badan Penelitian dan Pengembangan Kesehatan [Internet]; 2013 [diakses pada 20 Februari 2020], Tersedia pada:http://labdata.litbang.kemkes. go.id/images/download/laporan/RKD/2013/ Laporan_riskesdas_2013_final.pdf

7. Sugiyono, 2008. Metode penelitian kuantitatif, kualitatif dan R\&D. Bandung: Alfabeta.

8. Besada D, Goga A, Daviaud E. Rohde S, Chinkonde JR, Villeneuve S, et al. Roles played by community cadres to support retention in PMTCT Option $\mathrm{B}+$ in four African countries: a qualitative rapid appraisal. BMJ Open [Internet]. 2018 [diakses pada 19 Februari 2020];8(3):1-1. Tersedia pada: https://www. ncbi.nlm.nih.gov/pmc/articles/PMC5875612/ pdf/bmjopen-2017-020754.pdf

9. Kementerian Kesehatan. Peraturan Menteri Kesehatan Nomor 65 Tahun 2013 tentang pedoman pelaksanaan dan pembinaan pemberdayaan masyarakat bidang kesehatan. Jakarta: Kementerian Kesehatan RI [Internet]; 2013 [diakses pada 19 Februari 2020]. Tersedia pada: https://peraturan.bkpm.go.id/ jdih/userfiles/batang/PMK\%20No.\%2065\%20 $\operatorname{ttg} \% 20$ Pemberdayaan $\% 20$ Masyarakat $\% 20$ Bidang\%20Kesehatan.pdf

10. Nugraheni WP, Hartono RK. Strategi penguatan program Posbindu penyakit tidak menular di kota Bogor. Jurnal Ilmu Kesehatan Masyarakat [Internet]. 2018 [diakses pada 20 Februari 2020];9(3):198-206. Tersedia pada: http://jikm.unsri.ac.id/index.php/jikm/article/ download/886/pdf

11. Sunartyasih R, Linda B. Hubungan kendala pelaksanaan Posbindu dengan kehadiran lansia di Posindu RW 08 Kelurahan Palasari Kecamatan Cibiru. Seminar Nasional Penelitian dan PKM: Sains, Teknologi dan Kesehatan [Internet]. Bandung: STIKes Santo Borromeus. 2012 [diakses pada 18 Februari 2020. Tersedia pada: http://proceeding.unisba.ac.id/index.php/ sains_teknologi/article/view/699/pdf

12. Fauzia F. Analisis pemanfaatan pos pembinaan terpadu penyakit tidak menular di wilayah Puskesmas Warung Jambu Kota Bogor tahun 2013 [Abstrak Tesis]. Depok: Universitas Indonesia [Internet];2013 [diakses pada 19 Februari 2020], Tersedia pada: http://lib.ui.ac. id/file?file=pdf/abstrak-20348687.pdf

13. Purwanto, 1999. Psikologi Umum. Jakarta: Rineka Cipta

14. Sunaryo. 2004. Psikologi. Jakarta: EGC

15. Logen Y, Balqis, Darmawansyah. Faktor Yang Berhubungan Dengan Pemanfaatan Pelayanan Kesehatan Oleh Pemulung Di TPA Tamangapa. 2015. Fakultas kesehatan masyarakat, Universitas Hasanudin [internet]. Diakses pada 19 februari 2020, Tersedia pada : https://core. ac.uk/reader/77622001

16. Dwikurniarini D. Peranan perempuan di luar rumah tangga dalam persfektif historis. Mozaik [Internet]. 2007 [diakses pada 19 Februari 2020 ]; 2 (1): 1-16. Tersedia pada: https://journal.uny. ac.id/index.php/mozaik/article/view/4490/3890

17. Soeroso S. Masalah kesehatan remaja. Sari Pediatri [Internet]. 2001 [diakses pada 18 Februari 2020]; 3 (3): 190-198. Tersedia pada: https://saripediatri.org/index.php/sari-pediatri/ article/download/1000/930

18. Coker TR, Sareen HG, Chung PJ, Kennedy DP, Weidmer BA, Schuster MA. Improving access to and utilization of adolescent preventive health care: The perspectives of adolescents and parents. Journal of Adolescent Health [Internet]. 1 Agustus 2010 [diakses pada 19 Februari 2020] ;47(2):133-42. Tersedia pada: https://www. jahonline.org/article/S1054-139X(10)00024-8/ fulltext

19. Kurnia AR, Widagdo L, Widjanarko B. Analisis Ffktor yang berhubungan dengan kunjungan 
masyarakat usia produktif (15-64 Tahun) di Posbindu PTM Puri Praja Wilayah Kerja Puskesmas Mulyoharjo, Pemalang. Jurnal Kesehatan Masyarakat [Internet]. 1 Oktober 2017 [diakses pada 20 februari 2020] ;5(5):949957. Tersedia pada: https://ejournal3.undip. ac.id/index.php/jkm/article/view/19223

20. Sicilia G, Dewi FST, Padmawati RS. Evaluasi kualitatif program pengendalian penyakit tidak menular berbasis Posbindu di wilayah kerja Puskesmas Muara Bungo I. Jurnal Kebijakan Kesehatan Indonesia: JKKI [Internet]. 2018 [diakses pada 20 Februari 2020];7(2):88-92. Tersedia pada https://jurnal.ugm.ac.id/jkki/ article/view/36117/22614

21. Putri RE, Hubaybah H, Asparian A. Evaluasi proses implementasi Posbindu PTM Di Wilayah Kerja Puskesmas Simpang Sungai Duren Kecamatan Jambi Luar Kota Kabupaten Muaro Jambi Tahun 2017. Jurnal Kesmas Jambi [Internet]. 2018 [diakses pada 20 Februari 2020];2(1):12-27. Tersedia pada: https://onlinejournal.unja.ac.id/jkmj/article/view/6536/4156 